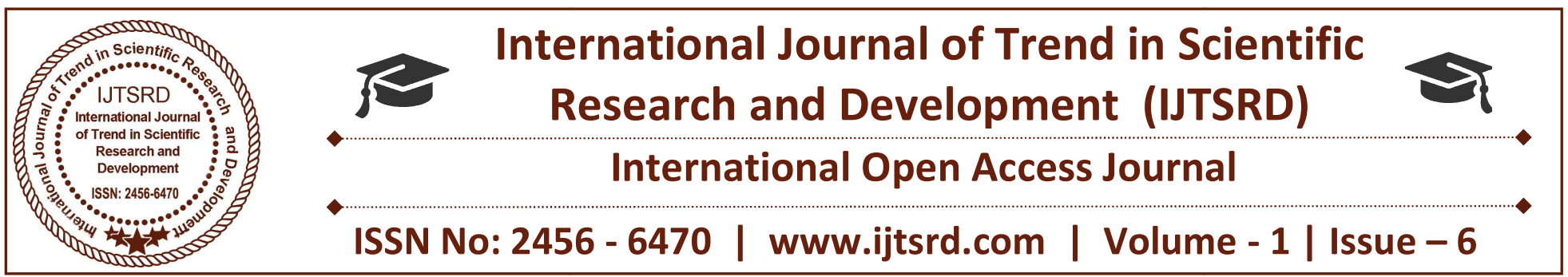

\title{
A Review Paper on Solar Panel Based Smart Irrigation System using GSM Module
}

Prof. Madhav Thigale

Department of Electronics and

Telecommunication, Dr. D Y Patil College of

Engineering, Management \& Research,

SavitribaiPhule Pune University, Akurdi, Pune

\section{Aniket Gholap}

Department of Electronics and

Telecommunication, Dr. D Y Patil College of

Engineering, Management \& Research,

SavitribaiPhule Pune University, Akurdi, Pune

\author{
Rohit Alate \\ Department of Electronics and \\ Telecommunication, Dr. D Y Patil College of \\ Engineering, Management \& Research, \\ SavitribaiPhule Pune University, Akurdi, Pune

\begin{abstract}
Akash Padman
Department of Electronics and

Telecommunication, Dr. D Y Patil College of

Engineering, Management \& Research,

SavitribaiPhule Pune University, Akurdi, Pune
\end{abstract}

\section{ABSTRACT}

Solar powered smart irrigation systems are very useful for farmers. Solar energy has emerged as viable source of renewable energy over the past few decades and is now used for various applications such as emergency lighting, water heaters, and industrial application. It is a cheap source of energy. The system consists of water pump which is solar powered with a moisture sensor used for automatic water flow control, light ambient sensor, Temperature sensor and GSM technology. It has mainly working in two modes i.e. manual mode and automatic mode. We have provides a switch which controls that mode in this RF transmitter and RF receiver will be used to operate the overall system. A polar single axis solar panel tracker is implemented and it has an adjustable horizontal motor controlled axis and fixed vertical axis. If 2 to 3 degrees of misalignment happens then the tracker will correct its position and prevents wastage of power by continuously running motor. The light intensity of the two LDR is compared and according to the higher intensity of LDR the rotation of solar panel is decided and it is adjusted. To prevent the panel from rotating $360^{\circ}$ the stepper motor will have overturn triggers.

Keywords: $\quad$ PICcontroller(PIC18F452), LCD, Moisture Sensor Temperature Sensor, Ambient Light Sensor, DC Motor, RF trans-receiver, Solar Pane

\section{INTRODUCTION}

Irrigation is the most important cultural practice and most labor intensive task in daily agriculture sector. Solar energy is the most abounding supply of energy within the world. Solar power isn't solely associate degrees were a solution to today's energy crisis however conjointly an environmental friendly type of energy. Solar High-powered irrigation system may be an appropriate different for farmers within the gift state of energy crisis. System uses alternative energy that drives water pumps to pump water from bore well to a tank. To do this automatically, sensors and methods are available to determine when plants may need water The main aim of this paper is to develop a PIC controller based system to irrigate the plant automatically. This system also supports water management decision, which determines the controlling time for the process. Through correct irrigation technologies, average vegetable yields may be maintained or increased. 


\section{BLOCK DIAGRAM}

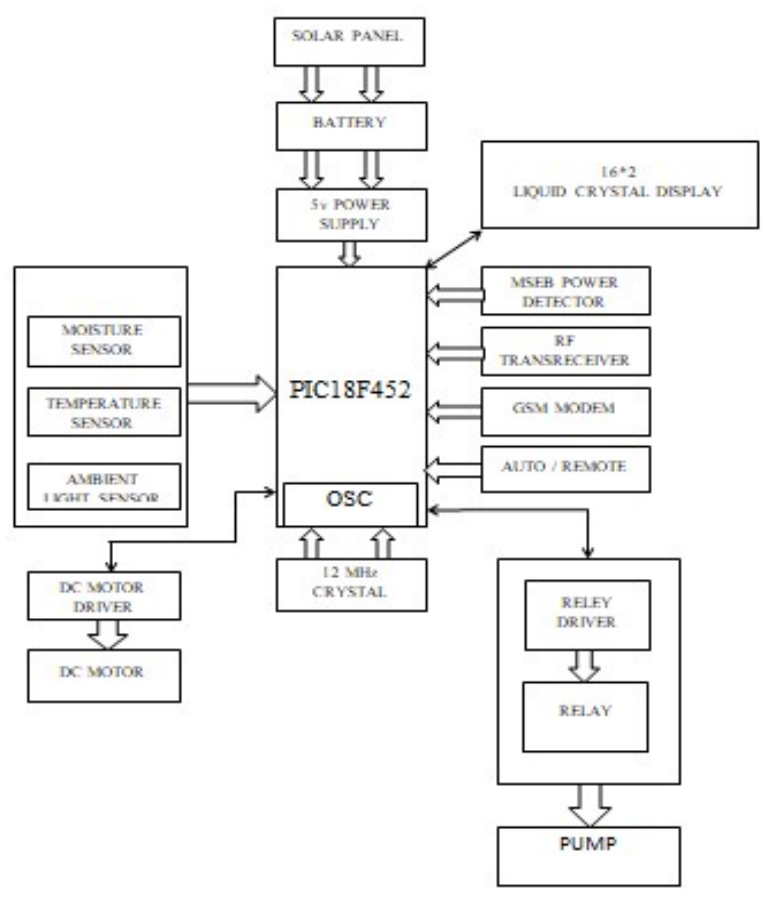

Fig: Solar Panel Based Smart Irrigation System Using GSM Module

\section{LITERATURE SURVEY}

Bureau of Electrical Energy in India in 2011 says there are around 18 million agricultural pump sets and around 0.5 million new connections per year is installed with average capacity 5HP. In agriculture sector total annual consumption is 131.96 billion KWh (19\% of total electricity consumption)

Y. P. Patil: Author proposed the automatic system based on ARM and GSM technology is used for communication. In this system Automatic irrigation technique irrigated using wireless sensor network. Photovoltaic cells are used to provide efficient power supply. If the water level reaches at certain high level, automatically motor will be turned off and it will provide notification to the farmer through GSM.

Rupali S. Sawant: In this author proposed a microcontroller based automatic irrigation system. This system uses 8051 microcontroller series. The system has soil moisture sensor, temperature sensor, humidity sensor and solar panel. When the moisture level of the soil changes the threshold value, it will direct the microcontroller whether it should pump the water or not. Humidity sensor is used to checks the temperature of the surrounding area.

Muhammad et al (2010): Irrigation control system builds using Artificial Neural Network Controller.
The proposed system is compared with ON/OFF controller. On the other hand ANN based approach has resulted in better and more efficient control system. A prior knowledge of system is not needed and have inherent ability to adapt to the changing conditions unlike conventional methods. ANN based systems can save lot of resources like energy and water and can provide optimized results to all type of agriculture areas.

Chaitali et al (2014): The Microcontroller and soil moisture sensor and temperature sensor based irrigation system. This system is a model to modernize the agriculture industries at a large scale with optimum investment. An irrigation model is proposed using different circuits.

\section{PROPOSED WORK}

The solar based irrigation can be done in following manner. To save large quantity of water and avoid wastage Drift irrigation system is used. The moisture level in soil is sensed by moisture sensor. The water level sensor is used to sense the water level in storage tank and to check whether the water is sufficient or not for watering the fields. A threshold value is decided and if water level sensed by the sensor is below the actual value then a message is sent to the farmer's cell phone as, "water is not sufficient, watering cannot be completed", otherwise the text sent is "watering completed". Sensors give an analog voltage to ADC. Analog to digital conversion is done and then digital signal is sent as input to PIC controller for further processing like generating and sending text message to the farmer by GSM module, and to determine whether the paddy fields need to be watered or not. The GSM and the PIC controller are connected by means of IC MAX232.The control of pumping valve which is used for pumping water to storage tank, watering valve for irrigating fields and shed control whenever needed can be regulated by system as User sends controlling signals to the controller through GSM. The RF trans receiver is used for switching purpose and it's range is $10-12 \mathrm{~m}$. To charge a battery Solar panels are used for harnessing photovoltaic energy which is to be used as a power supply for the PIC controller based irrigation system operating at paddy field, thereby we using solar energy to save power. The digital values then provided as an input to PIC controller. PIC controller is interfaced with GSM Module, LCD, DC Pump. When the moisture content in the soil is low, automatically pump will turn $\mathrm{ON}$ and farmer will be 
notified with the information on mobile through GSM module.

Components used for proposed system are:

1. Solar panel

2. Battery

3. PIC controller

4. Stepper motor

5. DC Motor

6. Soil Moisture Sensor

7. Light Ambient Sensor

8. Temperature Sensor

9. Soil Moisture Sensor

10. RF trance Receiver

\section{ADVANTAGES}

[1] As we are using solar energy and it is renewable source of energy there is no issue of power.

[2] This makes increase in productivity and reduces water consumption.

[3] Require smaller water sources.

[4] This makes increase in productivity and reduces water consumption.

[5] Modifications can be done in the circuit as per requirements of the farmer.

\section{CONCLUSION}

This irrigation system improves sustainability as it allows cultivation in places with water scarcity.

As the proposed model will help to farmers for properly irrigate their paddy field automatically? The sufficient level of water in the soil is ensured by the proposed system. Thus, in the proposed system over irrigation can be avoided, under system, upper soil erosion and which will control the wastage of water.

The system is economical. It doesn't need man power on duty it is so easy and reliable.

\section{REFERENCES}

1) Handley D, Vaux Jr. HJ, Pickering N (1983) Evaluating low-volume irrigation systems for emission uniformity. Calif $\mathrm{Ag}$ 37(1 and 2):10.

2) Letey J, Dinar A, Knapp KC (1985) Crop-water production function model for saline irrigation waters. Soil SciSoc Am J 49:1005

3) RanaBiswas, RomitBeed, AnkitaBhaumik, ShamikChakrabarty, RaghavToshniwal, "Inter national Journal of Advanced communication Engineering and Global Technology", I, vol. 03, no. 01, January 2015.

4) Thompson GT, Spiess LB, Krider JN (1980) Farm resource and system selection. In: Jensen ME (ed) chap 3: Design and operation of farm irrigation systems. AmSocAgrEng Monograph, pp 45-73

5) http://www.alldatasheet.com.

6) https://www.ashden.org 